\title{
Histopathologic and'bacterial evaluation of conventional and new copper amalgams
}

\author{
Donald R. Heys, Charles F. Cox, Ronald J. Heys, \\ WALTER J. LOESCHE AND J. K. AVERY \\ Department of Oral Biology, Dental Research Institute, University of Michigan, \\ Ann Arbor, Michigan, USA
}

\begin{abstract}
In vivo pulpal responses in monkeys and in vitro bacterial inhibition studies were completed on new copper amalgams, Sybraloy, ${ }^{\circledR}$ Dispersalloy, ${ }^{\circledR}$ Tytin ${ }^{\circledR}$ and a conventional Spheraloy ${ }^{\circledR}$ amalgam. Amalgams were placed in cavities lined with $\mathrm{ZOE}$ and in unlined cavities. Silicate and $\mathrm{ZOE}$ were used as controls. A total of 165 adult monkey teeth were evaluated at 3 days, 5 and 8 weeks. At 3 days the pulpal responses elicited by the copper amalgams appeared similar to conventional Spheraloy, ${ }^{\text {B }}$ all showing a slight to moderate response. At 5 weeks the majority of amalgams exhibited a slight pulpal response with a tubular reparative dentin under each restoration. The 8 week pulpal response showed a reduction of the inflammatory response characterized by a tubular reparative dentin with a uniform zone of predentin. Lined $\mathrm{ZOE}$ controls exhibited a slight response while silicate showed a moderate response with some persistent chronic inflammation. In vitro bacterial tests revealed that the various amalgams had little to no inhibitory effect on the three serotypes of $S$. mutans that are most prominent in humans.
\end{abstract}

\section{Accepted for publication 12 June 1978}

In an early histological study, Dixon \& Rickert (1933) observed the tissue response of copper amalgam in the backs and muscles of rabbits for a period of 5-6 months. The tissue responses were diagnosed as severe with active chronic inflammation which was characterized by extensive caseation necrosis about the amalgam with lymphocytic and fibroblastic exudate at the periphery. Manley (1936) demonstrated an immediate reaction to the pulps of dog teeth with destruction of the odontoblastic layer replaced by a mass of hyalin-like material from the placement of copper oxy-

This work was supported in part by Kerr Manufacturing Co., Romulus, Michigan. phosphate cement. Later studies by Manley (1944) on human pulps demonstrated a severe pulpal response with the use of copper phosphate cement. Effinger (1954) stated that the detrimental effect of copper cement and copper amalgam was due to the release of its mercury component. Mitchell observed the response of copper amalgam and a red copper cement in rat subdermal connective tissue for periods of 2-4 days, 12-18 days and 26-35 days. The response of the red copper cement varied from moderate to severe while the response of the copper amalgam was severe for all periods.

Manley (1942) noted early vascular changes under unlined silver amalgam pre- 
parations in dogs teeth; however there was no toxic effect producing a round cell infiltration. He indicated that human teeth tended to produce a more serious type of pulp response than teeth of smaller animals thus suggesting use of a liner. Seelig \& Lefkowitz (1950) found silver amalgam to be an innocuous filling material which showed no response in a shallow preparation. However, when used in deep cavities it produced a more severe response due to pulp compression, thermal shock and post-operative trauma. Studies by Nygaard-Östby (1955), Brännström (1963), and Langeland (1963) found that silver amalgam may produce a pulpal response with vascular changes, reduction of the odontoblastic layer, accumulation of leukocytes and deposition of a reparative dentin. James \& Schour (1955) reported a more severe reaction under deep cavities in which amalgam was placed. Swerdlow \& Stanley (1962) demonstrated the one day pulpal response of unlined silver amalgam to be more intense with more leukocyte accumulation than lined $\mathrm{ZOE}^{*}$ specimens. However, a gradual replacement of acute inflammatory cells by chronic cells with deposition of reparative dentin was noted over longer periods. Granath \& Möller (1971) also reported a more severe pulpal reaction under deep cavities. Mjör et al. (1977) studied the histological response of two new copper amalgams with a conventional unlined silver-tin amalgam and a ZOE lined cavity as controls. In the monkey teeth, both $\mathrm{ZOE}$ and silver-tin amalgams resulted in no or slight pulp reactions in deep or moderately deep cavities. In primary teeth, a new copper amalgam, (Neo-Silbrin ${ }^{\circledR}$ ), caused a moderate to severe pulp response; cavity depths were similar to ZOE controls. The other new copper amalgam (Sybraloy ${ }^{\circledR}$ )

* Zinc oxide and eugenol. demonstrated slight to moderate pulp reactions over short observation periods, while longer time intervals revealed a slight response except in deep unlined cavities where the reaction was more severe.

Naegeli (1893) observed that metal exerted an oligodynamic action upon micro-organisms. Miller (1890) showed that mat gold exhibited a bacteriocidal action on agar plates. $\mathrm{He}$ later demonstrated that mercury, silver and copper were able to arrest growth of various mixed organisms of carious dentin. Other studies by Pickerill (1909), Staul (1921) and Hill \& Boester (1934) indicated that various copper amalgams and cements were sufficiently germicidal for clinical purposes. Both McCue et al. (1951) and Shay et al. (1956) demonstrated copper amalgam to be a good bacteriostatic agent in vitro, and Mathewson (1970) showed greater growth inhibition with copper amalgam compared to silver amalgam. In clinical observations, Granath \& Hakansson" Holma (1961) found that recurrent decay was much less prevalent next to copper amalgam than next to silver amalgam. Leirskar (1974) and Takahashi (1975) tested various silver, gold and copper amalgams on various cell culture systems and found that they exerted a cytotoxic effect on all tissues observed. Esperik (1977) tested copper amalgams for 7 days at $37^{\circ} \mathrm{C}$ in $50 \mathrm{ml}$ of saliva. Copper content of saliva showed Neo-Silbrin ${ }^{\circledR}$ having the largest release, while the rest of the copper amalgams fell far below. No dired relationship between copper dissolution and copper content of the amalgam 'was established.

The new high copper amalgams have been introduced because of their corrosion and creep resistance which is common to the gamma-2 phase of conventional silver amalgams. It is the purpose of this paper 
to evaluate in detail the in vivo pulpal response as well as the in vitro bacterial inhibition of three different copper containing amalgams, and further to compare them to both lined and unlined amalgam according to the guidelines of the American National Standards Committee MD 156 (1978) for Dental Materials and Devices.

\section{Material and Methods}

In vivo: pulp study

Class V cavities were made on the buccal Surface of 165 adult Rhesus monkey teeth. All animals were initially sedated with an intramuscular injection of $0.2 \mathrm{cc} / \mathrm{kg}$ of Ketamine ${ }^{\circledR}$ hydrochloride $(100 \mathrm{mg} / \mathrm{cc})$. Deep anesthesia was maintained by an I.V. injection of 1.2 to $1.9 \mathrm{cc}$ of sodium pentobarbitol $(50 \mathrm{mg} / \mathrm{cc})$. All cavities were prepared at high speed air turbine spray on the buccal surfaces using a \#35 carbide inverted cone bur. The cavities Were prepared leaving approximately volum of remaining dentin. The vidthetric dimension was $1 \frac{1}{2}$ times the width and three times the length of a \#35 carbide inverted cone bur. The burs were changed every fourth tooth.

The compounds evaluated in this study Were three copper amalgams, Sybraloy ${ }^{\circledR *}$, Tytin ${ }^{\circledR}+$, and Dispersalloy ${ }^{\circledR} \neq$. These were compared to a conventional silver amalgam, Spheraloy ${ }^{\circledR} \S$ and two controls *Sybraloy 8

Romulus, Michigan.

Pytin (097611) S. S. White, Philadelphia, †Disyivania.

Johnersalloy (HRI 8137-002840) Johnson \& $\S$ Spher, East Windsor, New Jersey.

Michigan. Cavitec 01541020 A zOE liner, Kerr Mfg. Co.,
Romulus, Michigan. zinc oxide eugenol $(\mathrm{ZOE}) \|$ and silicate**. All of the amalgams were equally distributed in unlined and $\mathrm{ZOE}$ lined cavities.

Placement of all compounds was predetermined by random selection with each compound placed in both anterior and posterior teeth of both arches. Each copper amalgam compound was placed in 10 cavities at each test period while the controls were placed in five teeth for each time period. All compounds were histologically evaluated at three time periods: 3 days, 5 weeks and 8 weeks as recommended by the American Dental Association standards. At the end of the experimental time periods the animals were sedated and perfused through the left ventricle. The bodies were flushed with $0.9 \%$ physiologic saline, followed by a $20 \mathrm{~min}$ flush of an alcohol-formalin-acetic acid fixative (AFA), Cox et al. (1977). Immediate removal of the upper and lower jaw was followed with each tooth being cut from the alveolus with a surgical bone bur. The apical third of each tooth was removed with a low-speed surgical bone bur and the tooth post-fixed in AFA. All teeth were decalcified with end point determination made by radiographs. All teeth were dehydrated in ethyl N-butyl alcohol and embedded in Paraplast Plus ${ }^{\circledR *}$. Serial sections at eight microns were taken through the pulpal zone to provide a histological evaluation of each tooth. Slides were alternately stained with hematoxylin and eosin, Brown and Brenn for bacteria, and Herovici's polychrome. To control bias, the slides were independently evaluated by each investigator prior to their knowledge of the materials placement code. Histological evaluation of the tissues was based on criteria by Stanley

\footnotetext{
** M.Q. 35507 Liquid 166602 Powder Silicate Cement, S.S. White, Philadelphia, Pennsylvania.

* Sherwood Medical Industries, St. Louis, Missouri.
} 
et al. (1967) and Langeland (1963) with modifications of Mjör \& Tronstad (1972).

A slight response at 3 days is typified by disruption and edema of the odontogenic and subjacent cellular zones. The longer time periods of 5 and 8 weeks present a change in response with persistence of inflammatory cells. Reparative dentin is not present at 3 days; however, at 5 and 8 weeks a zone of tubular dentin should be present. The predentin zone is reduced in width as compared to the other circumpulpal predentin. Its border may be slightly scalloped with a continuous pallisade arrangement of odontoblasts that may appear shorter or wider than other nonirritated odontoblasts.

A moderate reaction at 3 days is characterized by a distinct increase of inflammatory cells within the odontogenic layer with displacement of nuclei into the tubules. At 5 and 8 weeks the odontoblastic zone has become reorganized with discontinuous pallisade cells that may show nuclei which are displaced into the dentinal tubules. The reparative dentin may be of either a tubular or cellular nature with a predentin zone that is reduced in width as compared to the remaining pulp.

A severe response at 3 days is marked by a cellular infiltration of lymphocytes below the pulp tissue subjacent to the dentin underlying the cavity preparation. Hyperemia is seen around the cellular infiltrates with areas of hemorrhage. The odontoblastic layer is disrupted or destroyed with displaced nuclei. At 5 and 8 weeks, the reparative dentine is dystrophic with cellular inclusions. A persistence of neutrophitic leukocytes is evident around the damaged area.

Measurements of the remaining and reparative dentin were carried out on all specimens using a Zeiss photomicroscope.
The shortest distance from the cavity floor to the pulp was measured and, in similar fashion, the largest amount of reparative dentin was measured after 5 and 8 weeks.

\section{In vitro: bacterial inhibition study}

Plaque and salivary samples were collected from children with rampant caries. These were serially dispersed and plated automatically using a spiral plater* on $\mathrm{MM}^{10}$ sucrose agar and/or MSB agar, within 2 to $3 \mathrm{~h}$ after collection (Loesche et al. 1977). Freshly prepared amalgam pellets cor responding in size to a Class I preparation were made of the previously mentioned alloys and evenly placed on each agar plate. The plates were incubated anaerobically for 4 to 7 days at $37^{\circ} \mathrm{C}$ in an atmosphere of $85 \% \mathrm{~N}_{2}, 10 \% \mathrm{H}_{2}$ and $5 \% \mathrm{CO}_{2}$. The plates were then examined under a stereoscopic microscope to determine whether inhibition of bacterial growth occurred about the amalgams. Minimal inhibition corresponded to an absence of growth in a 0.5 to $1.0 \mathrm{~mm}$ wide border about the amalgam. The total colony forming units (CFU) of $S$. mutans and $S$. sanguis colonies on the $\mathrm{MM}^{10}$ sucrose and MSB plates were also enumerated.

In separate experiments stock cultures of $S$. mutans were inoculated into trypticase soy broth (TSB) which contained cubes of the four amalgams. The purpose of this study was to determine whether soluble materials from the amalgams would diffuse into the broth and inhibit broth growth of the cultures of whether the amalgams would inhibit of reduce adherent growth of $S$. mutans on its surfaces. Each of the four amalgams was triturated and condensed into plastic molds to form $2.5 \mathrm{~mm}^{3}$ cubes. One side of

* Exotect Co., Gaithersburg, Maryland. 
each cube was smoothed with Moore's $\dagger$ fine sand disc and polished with XXX silex and tin oxide slurries on Robinson* soft cup brushes. A hole was drilled into the amalgam to accept a "press fit" of a stainless steel wire which was in turn suspended from the cap of a broth tube. The amalgam assembly was autoclaved and transferred to tubes containing $3 \mathrm{ml}$ TSB broth with $1 \%$ sucrose which had been inoculated with an overnight culture of either $S$. mutans strain G55 (serotype d), 6715 (serotype d) or B2 (serotype e). These serotypes are the predominant $S$. mutans serotypes found in man (Bratthall 1972). The amalgam cubes were transferred daily to fresh broth. The spent broth was vortexed and its turbidity read at $520 \mathrm{~nm}$ on the Gilford spectrophotometer**. After three serial passages, the amalgam cubes were aseptically transferred to tubes containing $10 \mathrm{ml}$ of reduced transport fluid (RTF) Loesche et al. (1977) and sonified for 25 seconds. The RTF was diluted and plated on MM10 sucrose plates with the spiral plater. Viable counts were obtained after 3 days of anaerobic growth. Controls consisted of the TSB broth without an amalgam cube connected to the steel wire. The wire was serially passed and the turbidity of the resultant culture was taken as the control value against which the amalgams were evaluated for inhibition.

\section{Histological - 3 day}

\section{Results}

The 3 day pulpal response of the new Coppers, Sybraloy ${ }^{\circledR}$ (Fig. 1), Tytin ${ }^{\circledR}$ and Dispersalloy ${ }^{\circledR}$ (Fig. 2), and the conventional silver amalgam Spheraloy in

† E. C. Moore Co., Dearborn 2, Michigan.

Y Buffalo Dental Mfg. Co., Inc., Brooklyn, New ***

* Gilford Instrument Co., Oberlin, Ohio. unlined cavities fell within the range of slight to moderate. In those teeth classified slight, the inflammatory response was minimal. There was always disorganization of the odontoblast layer with occasional displaced nuclei. The more moderate responses were found in teeth with less remaining dentin and characterized by small areas of vacuolization in the odontoblastic layer. In all teeth the affected pulp was below the cavity preparation while the remaining pulpal architecture appeared normal.

Sybraloy ${ }^{\circledR}$, Tytin ${ }^{\circledR}$, Dispersalloy ${ }^{\circledR}$ and Spheraloy were also placed in cavities which were lined with ZOE. All amalgams tested were similar in their pulpal response at this time. The majority of the responses were in the slight category with minimal displaced cells and disruption of the odontoblast zone and a few inflammatory cells. A few teeth were classified moderate. This response was found in teeth with deep cavity preparations and characterized by displaced cells, disruption of odontoblast region and more inflammatory cells than observed with a slight response.

The 3 day pulpal response of $\mathrm{ZOE}$ (Cavitec ${ }^{\circledR}$ ) (Fig. 3) control showed a minimal inflammatory response which was limited to the cells subjacent to the cut dentin. There was a disruption of the odontoblastic layer with a hyperemia and associated round cell infiltration. Odontoblastic nuclei were generally displaced into the dentinal tubules.

- Three day silicate response was found to be moderate with many displaced odontoblast processes within the dentinal tubules, disruption of the odontoblast layer, and a moderate inflammatory response in the underlying pulp (Fig. 4).

5 week

The pulpal responses observed after a 


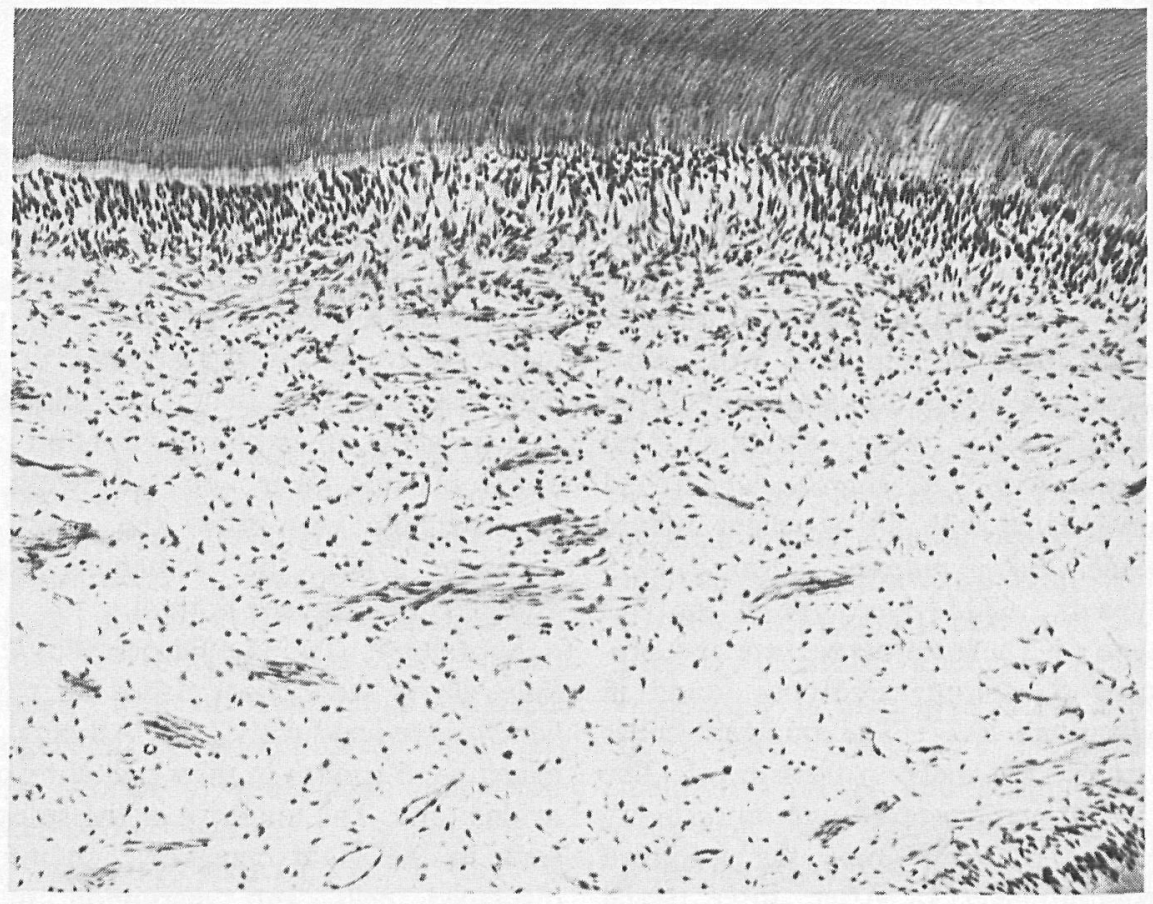

Fig. 1. Three day Sybraloy ${ }^{\circledR}$ shows a moderate response with disruption of the odontogenic zone, loss of predentin zone, some aspirated nuclei present in the dentinal tubules, and a moderate number of inflammatory cells.

Remaining dentin 790 microns. $\times 105$.

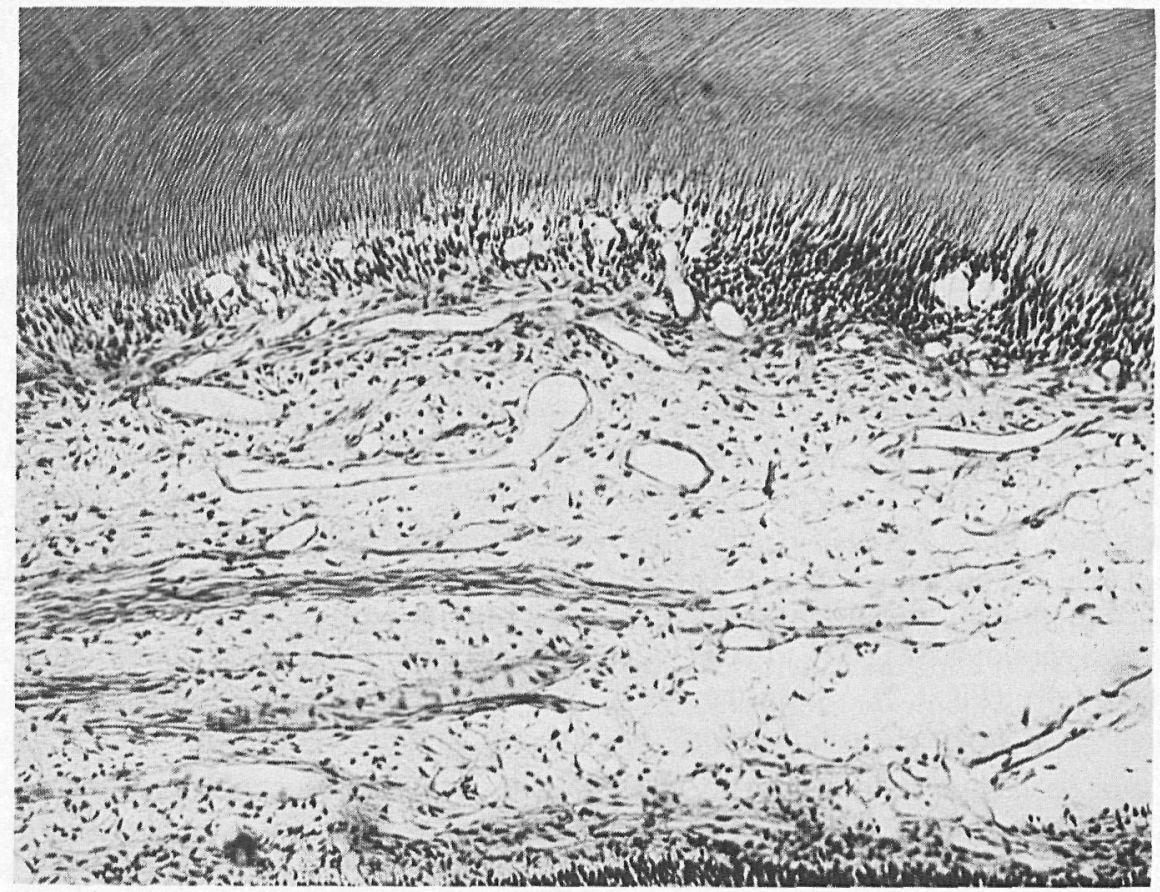

Fig. 2. Dispersalloy ${ }^{\circledR}$ after 3 days has a moderate response with some vacuolization of the odontoblast layer and some inflammatory cells in the underlying pulp.

Remaining dentin 522 microns. $\times 115$. 


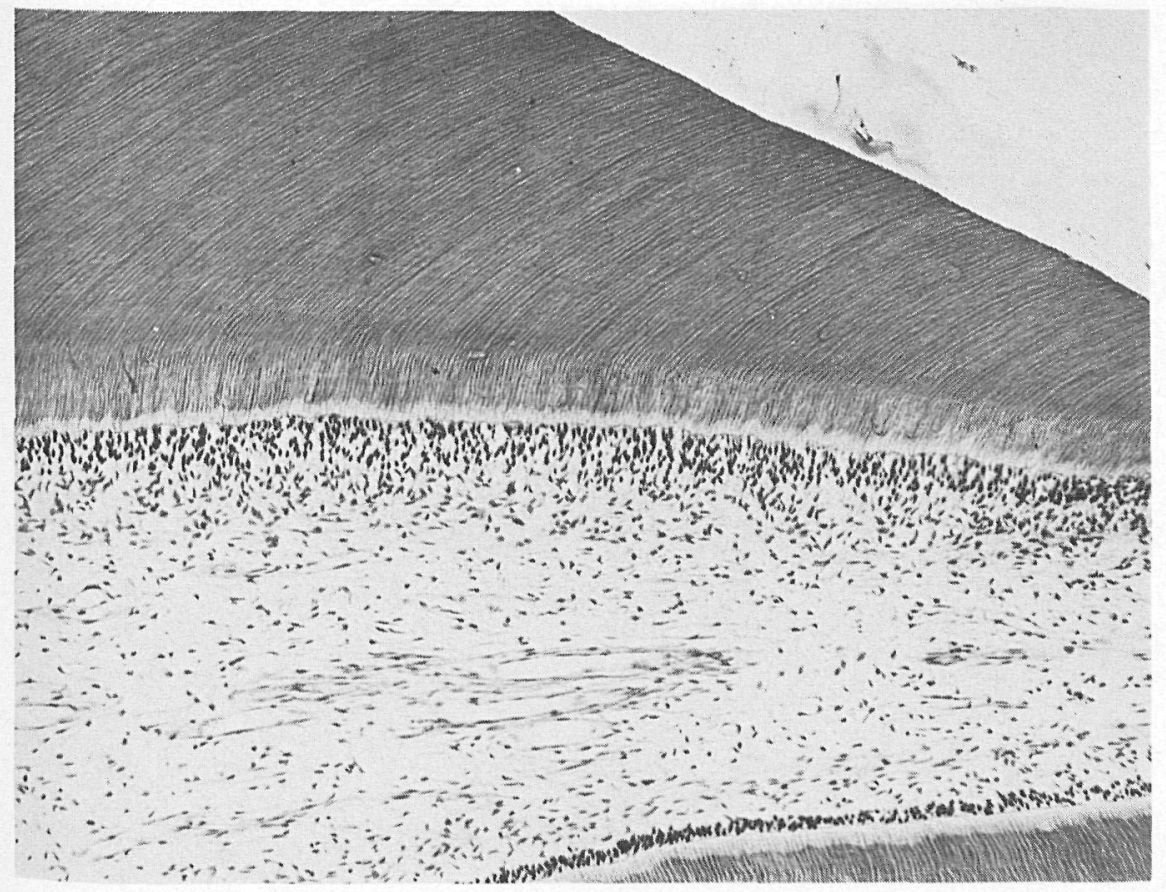

Fig. 3. This 3 day ZOE control has a slight response underlying a deep cavity preparation. Little if any odontoblast disruption is seen and very few inflammatory cells are present.

Remaining dentin 63 microns. $\times 105$.

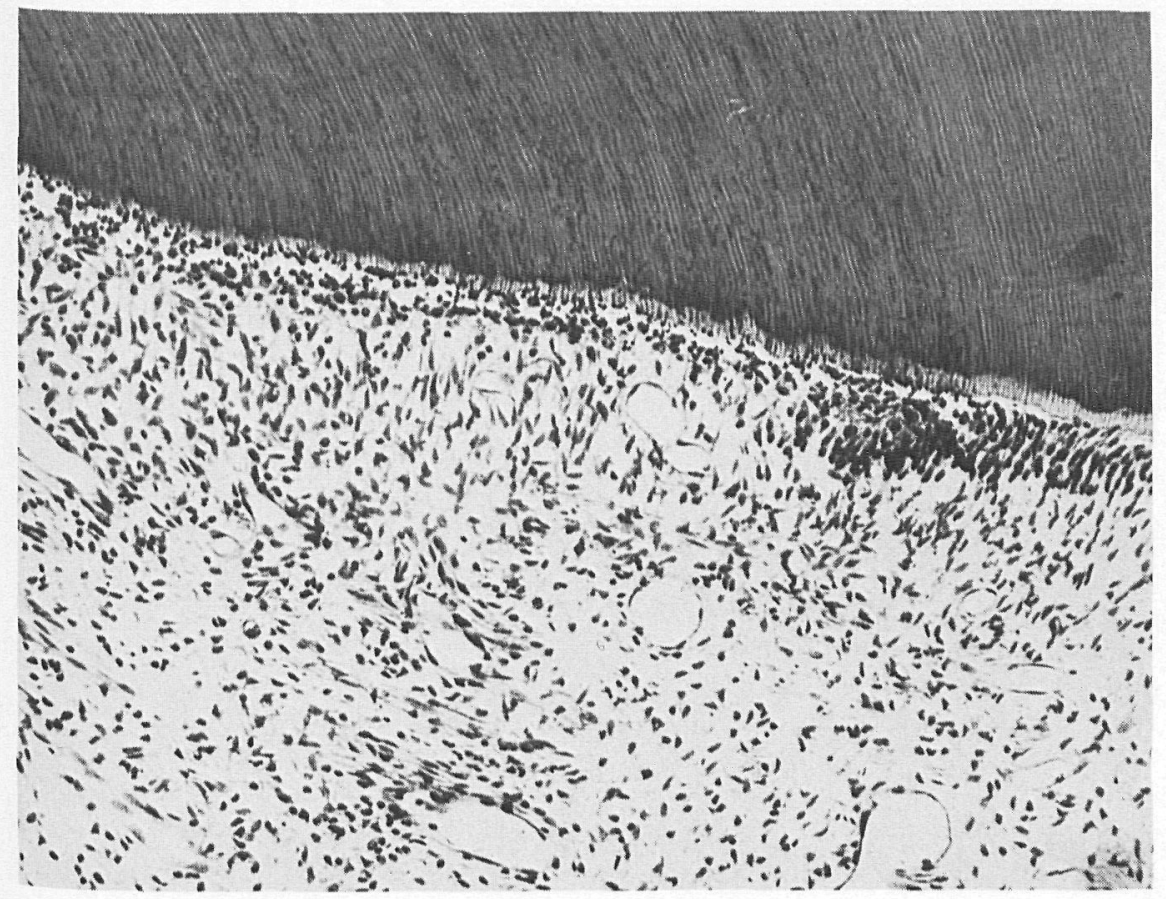

Fig. 4. Silicate after 3 days elicits a moderate response characterized by a loss of the columnar appearance of the odontoblast, a large number of aspirated nuclei, and a moderate inflammatory response.

Remaining dentin 630 microns. $\times 100$. 


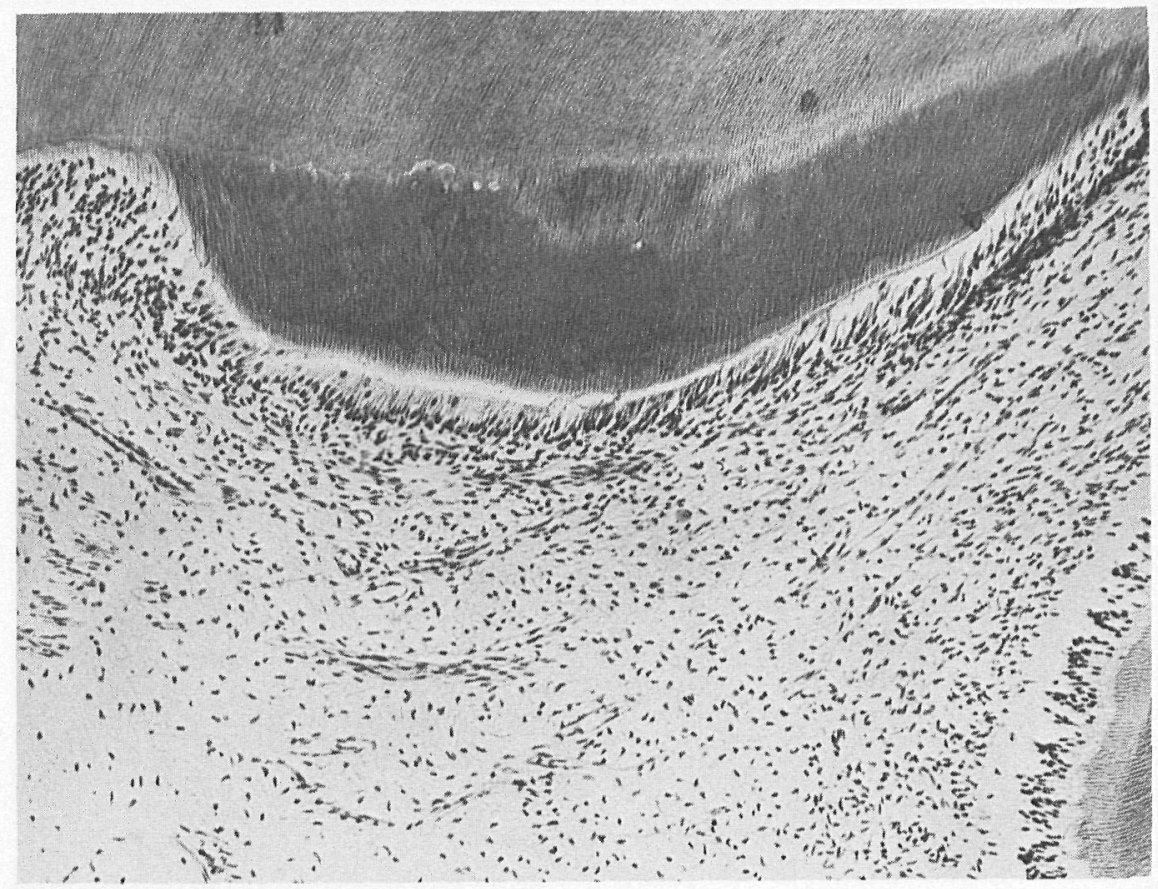

Fig. 5. This 5-week response of Dispersalloy ${ }^{\boxplus 0}$ reflects a slight response with a zone of tubular reparative dentin with a regular predentin zone, intact odontoblast layer and few inflammatory cells. Remaining dentin 810 microns. Reparative dentin 225 microns. $\times 130$.

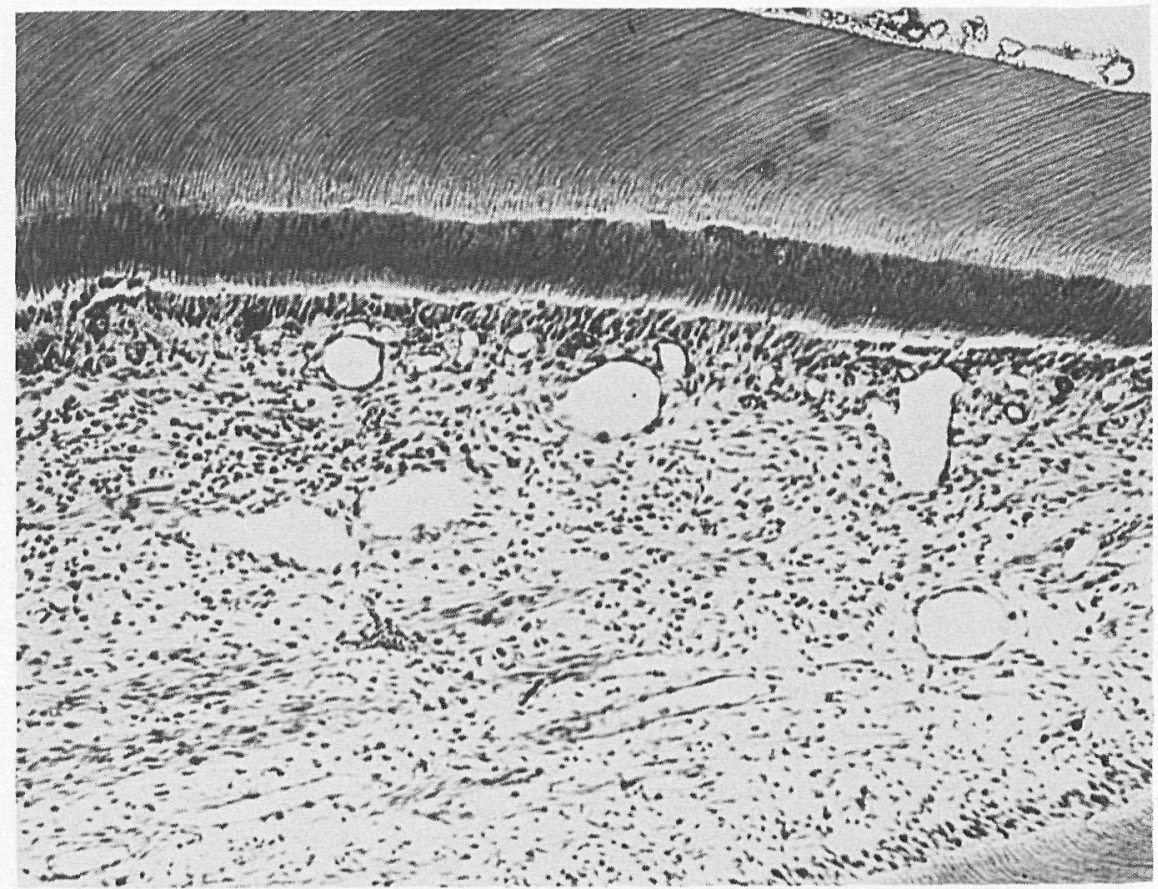

Fig. 6. This is one of the 5 -week specimens which had a moderate response. This is Spheraloy ${ }^{\circledR}$ in a very deep preparation with some disruption in the odontoblast layer, increased vascularity and a moderate number of inflammatory cells.

Remaining dentin 180 microns. Reparative dentin 90 microns. $\times 105$. 


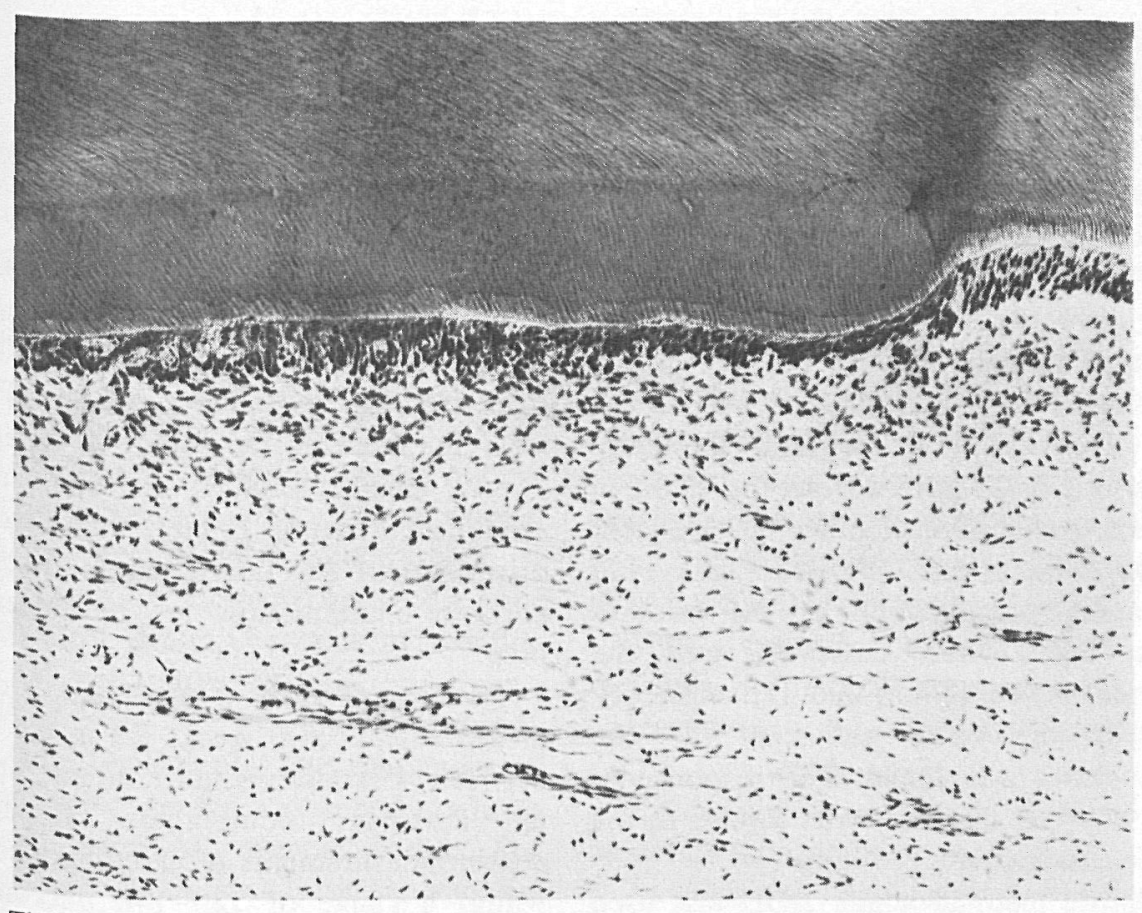

Fig. 7. This is a ZOE lined cavity with Sybraloy which has a slight response with tubular reparative dentin beneath the cavity preparation, a uniform odontoblast layer and few if any inflammatory cells.

Remaining dentin 1160 microns. Reparative dentin 163 microns. $\times 105$.

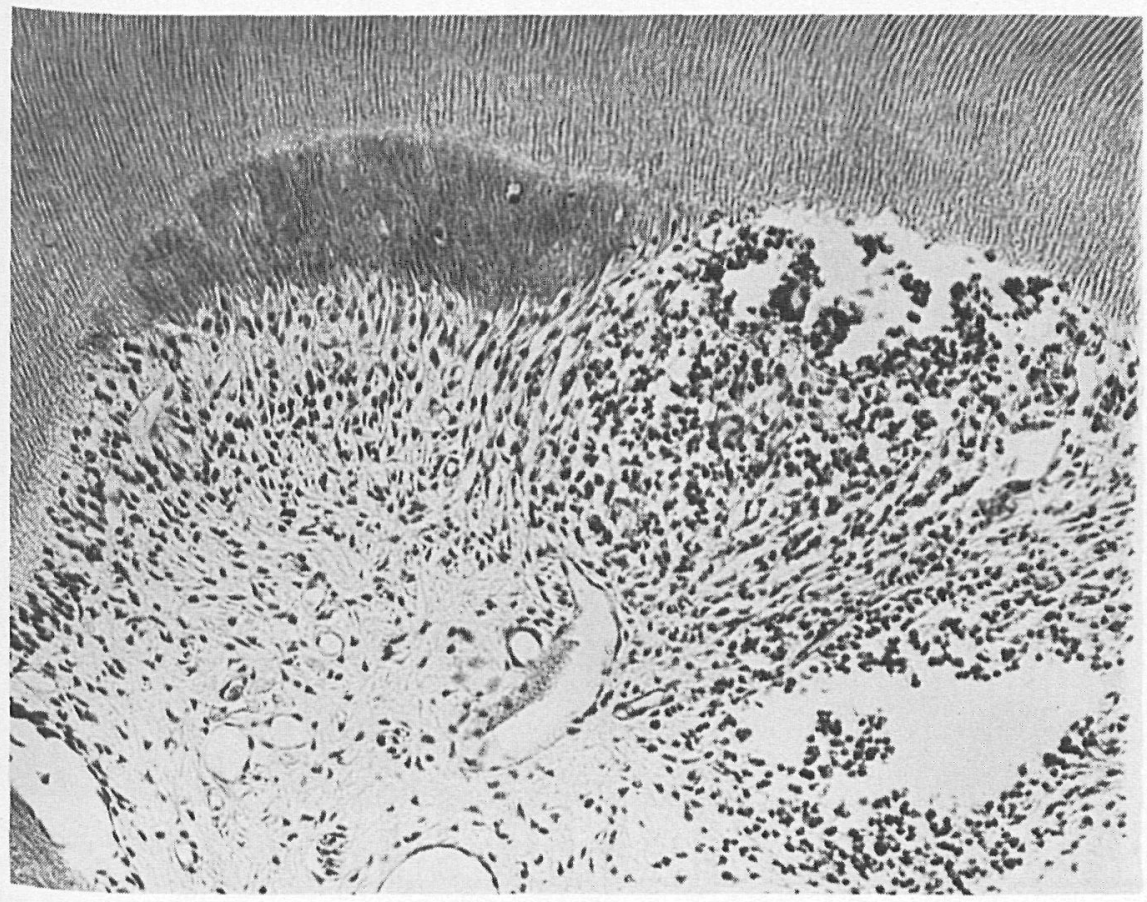

Fig. 8. This 5-week silicate response is moderately severe with entrapped cells in the reparative dentin and Rerger number of inflammatory cells with odontoblast break-down adjacent to the reparative dentin.

Remaining dentin 495 microns. Reparative dentin 135 microns. $\times 105$. 
period of 5 weeks showed a reduction from the response seen at 3 days. All the copper amalgams were similar in their histological response. The majority of the teeth exhibited a slight response although some were moderate. Regular reparative dentin, a minimal inflammatory response, and intact odontoblastic layer typified the slight response (Fig. 5). The moderate response (Fig. 6) differs from the slight in that the reparative dentin has frequent cellular inclusions. Disruption and occasional vacuolization of the odontoblastic layer were observed, and the presence of some chronic inflammatory cells in the area subjacent to the odontoblasts was noted. The response to Spheraloy at this time was similar to the copper amalgams.

In those teeth in which ZOE was used as a liner, all the copper amalgams had a slight response (Fig. 7). The conventional silver amalgam Spheraloy ${ }^{\circledR}$ was also judged to have a slight pulpal response: unlike the unlined cavities, no moderate responses were found.

ZOE controls at this time also showed a slight response, whereas the silicate controls showed a moderate to sever response. The response to silicate (Fig. 8) was characterized by a zone of reparative dentin which contained inclusions and a scalloped predentin border, with persistent disruption of the odontoblastic layer and chronic inflammation in the underlying pulp.

The average remaining dentin measurements at 5 weeks fell in the range between 450 microns and 750 microns for all amalgam compounds. Reparative dentin measurements of all compounds fell within a range of 120-140 microns for both lined and unlined cavities (Graph \#1). Analysis of the data has shown a $\cot ^{\circ}$

\section{GRAPH I \\ COMPARISON OF REMAINING \\ TO REPARATIVE DENTIN}

REMAINING DENTIN

reparative deniN

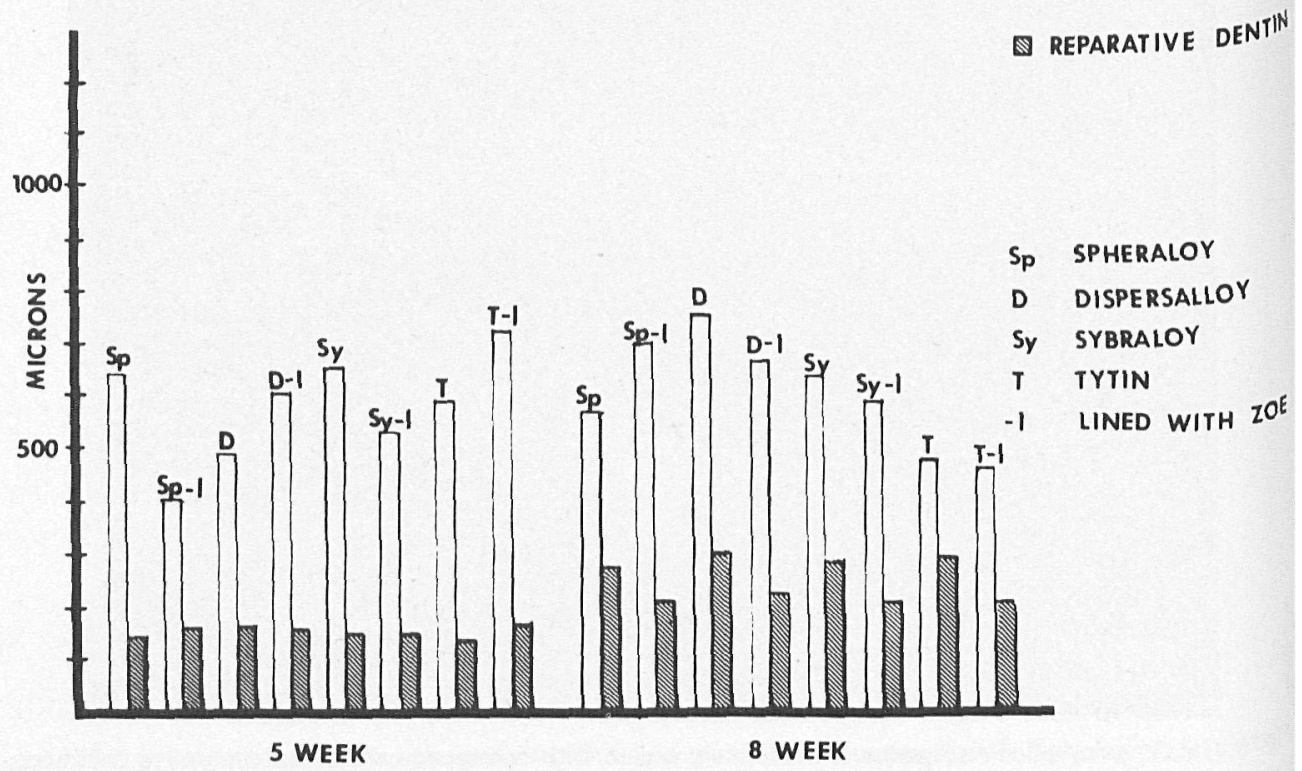


relation between remaining and reparative dentin. The less remaining dentin, the less reparative dentin is formed, and conversely the thicker the remaining dentin, the more reparative dentin is deposited.

8 week

The 8-week response of all amalgams tested showed a resolution of the inflammatory response. All unlined copper amalgams exhibited a slight response (Figs. 9 and 10) characterized by a zone of reparative dentin. Portions of the first zone of reparative dentin had some entrapped cells and irregularities present, with some exceptions. The remainder of the reparative dentin was tubular with a predentin zone of variable width. The odontoblastic layer was present, and the odontoblasts underlying the cut tubules were shorter and darker staining than those which were not affected by cavity preparation. The surrounding pulp was intact with few inflammatory cells present near the zone of reparative dentin. The response to Spheraloy ${ }^{\circledR}$ at this time was similar to the copper compounds (Fig. 11). All amalgams placed in cavities with a $\mathrm{ZOE}$ liner produced a slight response. Reparative dentin beneath these cavities was found to be more regular, containing less cellular inclusions that those in unlined cavities.

ZOE controls exhibited a slight response. The silicate response was characterized by irregular reparative dentin formation, some disruption of the odontoblastic zone and a slight to moderate inflammatory response.

Analysis of the data for reparative

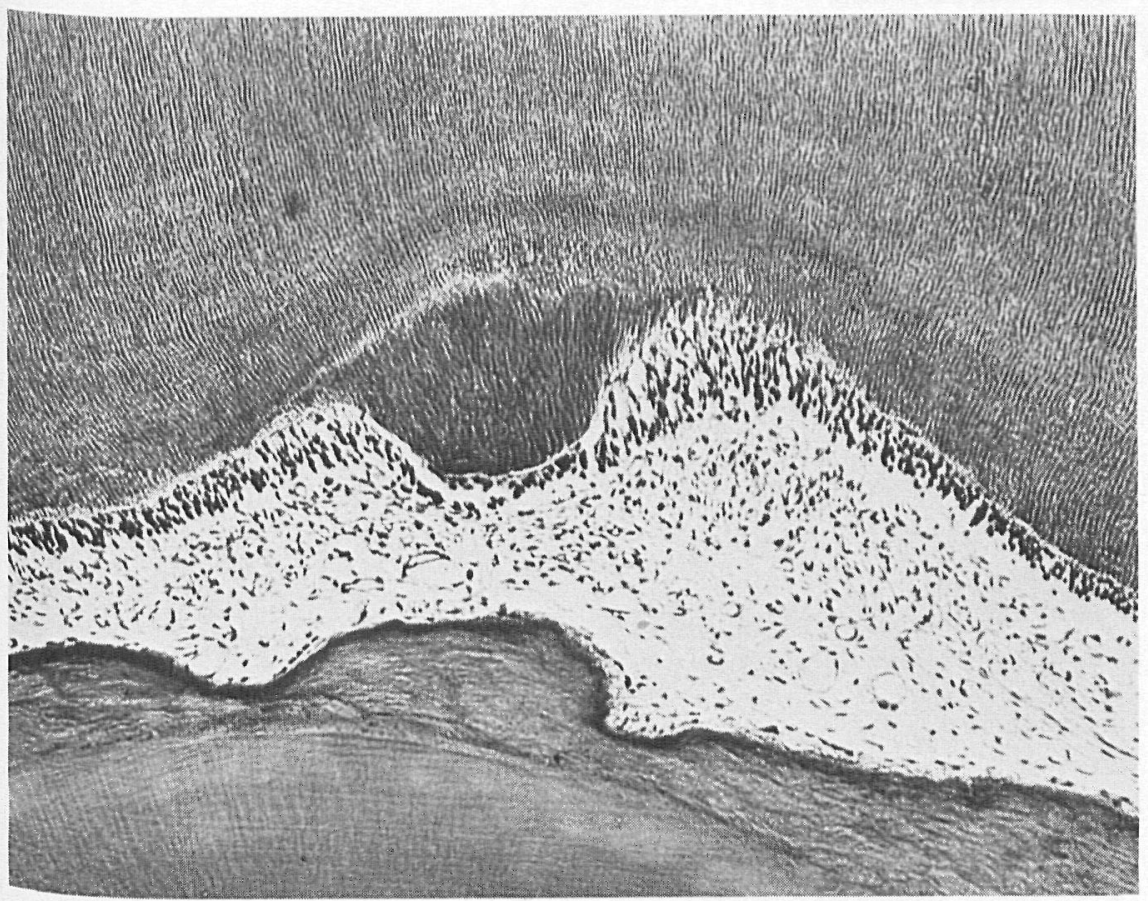

Fig. 9. Sybraloy after 8 weeks has a slight response with tubular reparative dentin, an intact odontoblast

Remain few if any inflammatory cells.

Remaining dentin 870 microns. Reparative dentin 306 microns. $\times 130$. 


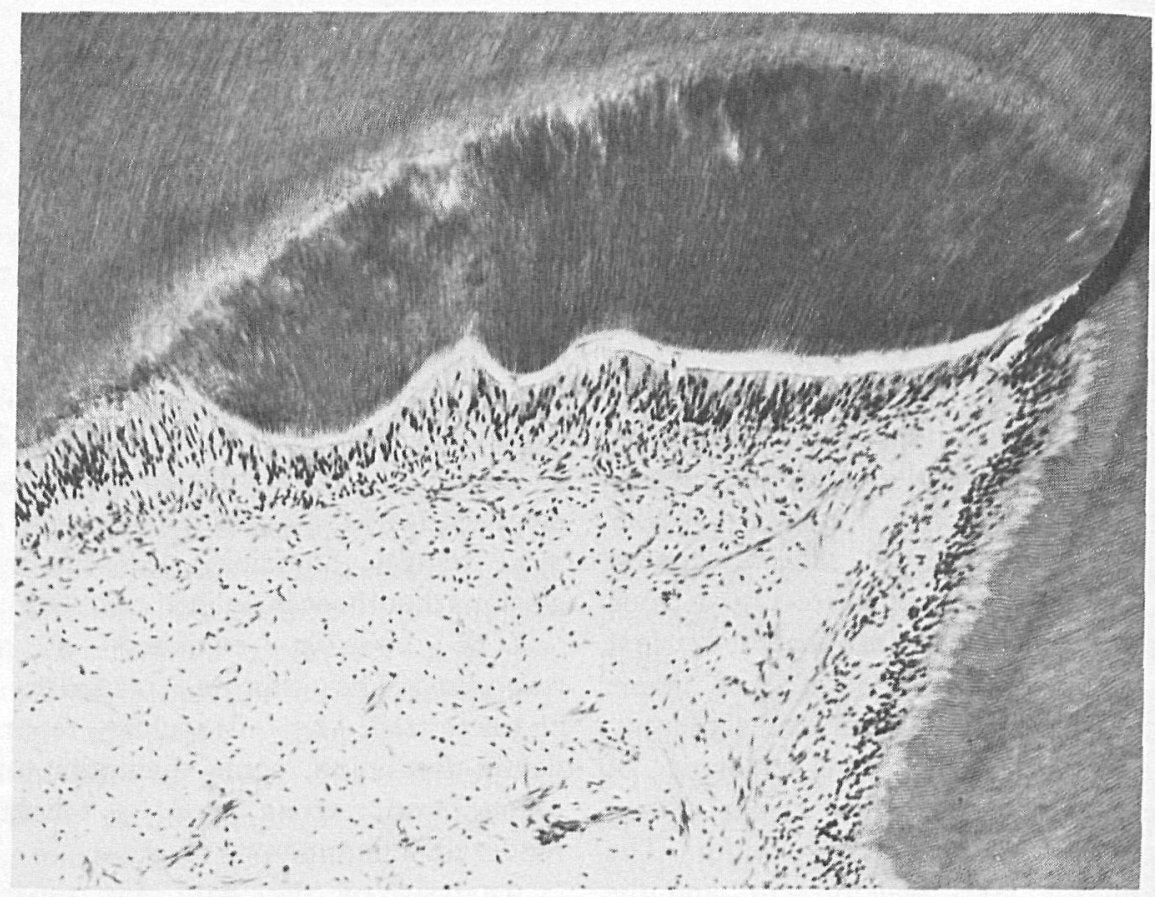

Fig. 10. The 8-week response of Dispersalloy ${ }^{\circledR}$ is slight with a minimal inflammatory cell response and zone of reparative dentin present.

Remaining dentin 870 microns. Reparative dentin 306 microns. $\times 105$.

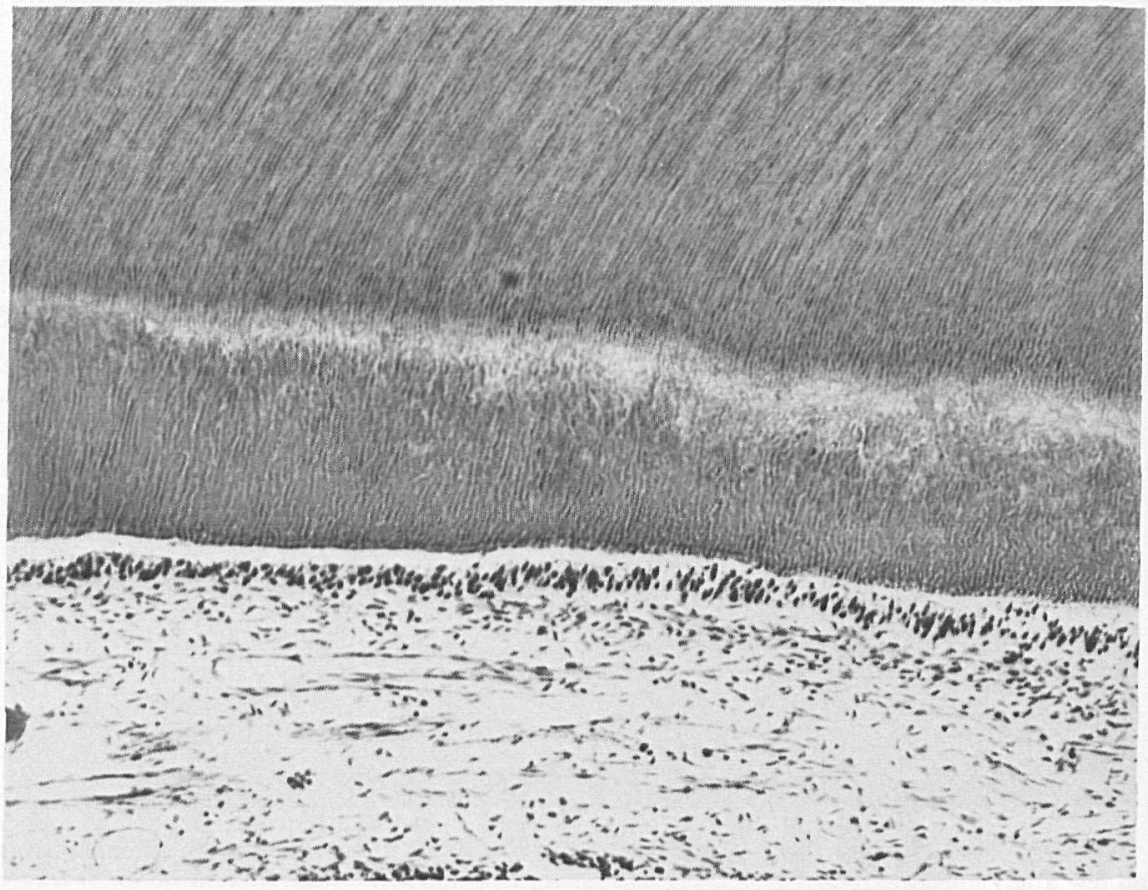

Fig. 11. The 8-week Spheraloy ${ }^{\circledR}$ is similar to the copper amalgams showing a slight response with little inflammatory response and a tubular reparative dentin zone present.

Remaining dentin 1363 microns. Reparative dentin 100 microns. $\times 130$. 
dentin at this time has shown no correlation or significant difference in the amount of reparative dentin between various compounds.

The remaining dentin measurements showed an increase in reparative dentin deposition of 100-200 microns over those observed at 5 weeks.

All unlined amalgams were measured and showed comparable amounts of reparative dentin for copper, silver amalgam and silicate.

Brown and Brenn stain demonstrated the presence of bacteria at the base of most unlined cavity preparations. In those teeth lined with $\mathrm{ZOE}$ no bacteria were observed on the cavity floor; however, bacteria were observed on lateral cavity walls near the dentino-enamel junction. No bacteria were observed within the dental tubules or pulpal tissue of any teeth tested.

In vitro results

Pellets of the four amalgams were placed on agar plates inoculated with either a plaque or a salivary sample.

The data are presented as follows:

Number of samples in which minimal inhibition occurred*

Amalgam preparation

\begin{tabular}{lccccc}
\cline { 3 - 5 } Source of bacteria & No. of samples & Sybraloy & Spheraloy & Tytin $^{\circledR}$ & Dispersalloy ${ }^{\circledR}$ \\
\hline Plaque & 15 & 5 & 7 & 1 & 3 \\
Saliva & 2 & 2 & 0 & 0 & 0 \\
Total & - & - & - & - & - \\
\hline
\end{tabular}

* Inhibition was confined to the immediate vicinity of the amalgam and was not impressive.

Minimal inhibition was noted in a few instances. This corresponded to an absence of growth in a 0.5 to $1 \mathrm{~mm}$ wide border about the amalgams. Spheraloy ${ }^{\circledR}$ and Sybraloy ${ }^{\circledR}$ exhibited this type of inhibition in seven of the 17 samples. No apparent inhibition of $S$. mutans or $S$. sanguis was noted on these plates.

All amalgams reduced the broth growth of $S$. mutans strains GS5 and 6715 relative to the control, but had no effect on strain B2, as seen in the following data:

Effect of various amalgams on broth cultures of S. mutans

GS5

6715

B2

Turbidity at $520 \mathrm{~nm}$

\begin{tabular}{|c|c|c|c|c|c|}
\hline Dispersalloy ${ }^{\circledR}$ & 0.60 & Dispersalloy ${ }^{\circledR}$ & 0.60 & Sybraloy ${ }^{\circledR}$ & 1.22 \\
\hline Sybraloy ${ }^{\circledR}$ & 0.63 & Sybraloy & 0.64 & Dispersalloy ${ }^{\circledR}$ & 1.25 \\
\hline Spheraloy ${ }^{\circledR}$ & 0.70 & Tytin & 0.65 & Spheraloy ${ }^{\circledR}$ & 1.34 \\
\hline Tytin ${ }^{\circledR}$ & 0.72 & Spheraloy ${ }^{\circledR}$ & 0.66 & Tytin ${ }^{\otimes}$ & 1.35 \\
\hline Control & 0.79 & Control & 0.79 & Control & 1.10 \\
\hline
\end{tabular}


Dispersalloy caused about a $25 \%$ reduction in the tubidity of strains GS5 and 6715 whereas Sybraloy ${ }^{\circledR}$ exhibited a $15 \%$ to $20 \%$ reduction. None of these differences was statistically significant.

The $S$. mutans strains also grew as adherent colonies on the amalgam surfaces. This growth was quantitated by measurements of the viable colony forming units obtained from each amalgam cube. As the cubes were made in identical molds, the surface area available for adherent growth would be similar among the various amalgams. Dispersalloy ${ }^{\circledR}$ was found to be most inhibitory relative to the other amalgams. This was especially true for strains GS5 and B2 as seen below:

Effect of various amalgams on surface growth

\begin{tabular}{lcccc}
\hline Strain & GS5 & 6715 & B2 & Average \\
\hline & $\times 10^{8}$ CFU per amalgam (a) & & \\
Dispersalloy ${ }^{\circledast 7}$ & 3.4 & 7.1 & 3.5 & 4.7 \\
Spheraloy & 7.5 & 1.5 & 19.0 & 9.3 \\
Sybraloy $^{\circledR}$ & 9.7 & 2.1 & 13.3 & 8.4 \\
Tytin & 23.7 & 1.7 & 11.6 & 12.3 \\
\hline
\end{tabular}

(a) Average of 2 to 3 separate determinations

This analysis indicates that Dispersalloy ${ }^{\circledR}$ was the most inhibitory to both broth and surface growth of the $S$. mutans strains, suggesting that it releases soluble inhibitors into the media. None of the differences, however, was statistically significant.

\section{Discussion}

It was the purpose of this study to evaluate in detail the in vivo pulpal response as well as the in vitro bacterial inhibition of three copper amalgams and a conventional silver amalgam. All pulpal responses were compared in $\mathrm{ZOE}$ lined cavities and unlined cavities in accordance with the American National Standards Committee MD156 for Dental Materials and Devices (1978).

The amalgams tested showed similar histological responses for each time period tested. The responses of the three copper amalgams were similar at 3 days and were observed to be slight to moderate; the same was true for Spheraloy ${ }^{\circledR}$. Those cavities lined with ZOE showed a milder response than unlined cavities. These observations agree with studies done by Manley (1942) in which he suggested the use of a liner to reduce the pulpal response to amalgams.

After 5 weeks all amalgam compounds stimulated $130 \pm 10$ microns of reparative dentin with a reduction in the pulpal response in lined teeth. Our 5 week data on reparative dentin have shown that, the deeper a cavity preparation, the less reparative dentin is formed and conversely, the shallower a cavity preparation, the more reparative dentin is formed. This $\mathrm{cor}^{5}$ relation suggests that more damage has occurred to the odontoblast in deep cavities, thereby requiring more time for cellular reorganization before dentin deposition can occur. In shallow cavities destruction and disorganization of the odontoblast is minimal and dentin deposi tion can start almost immediately, resulting in greater amounts of reparative 
dentin. No differences in the amounts of reparative dentin between the various compounds can be observed at this time. Both Spheraloy and the copper amalgams are similar in this response. Our findings are similar to those of Swerdlow \& Stanley (1962) who reported a mild pulpal response to silver amalgam with some degree of leukocyte accumulation, eventual reduction of inflammatory cells and deposition of tubular reparative dentin with a uniform predentin.

The histological 8-week results were similar to those observed after 5 weeks with a diminution in the number of inflammatory cells present. In contrast to the data observed at 5 weeks, 8-week reparative dentin measurements showed no correlation between depth of a cavity preparation and the amount of reparative dentin formed. A possible explanation for this is that once a certain amount of reparative dentin is formed beneath a cavity preparation, odontoblasts slow down dentin deposition. No statistical correlation in the amounts of reparative dentin between the various compounds can be stated, even though there were small differences. It may be that if the medicament is mildly irritating after 5 to 8 weeks, the reparative dentin acts as a barrier to peristent irritation from the compounds.

Our findings are similar to Mjör et al. (1977) in regard to Sybraloy ${ }^{\circledR}$ in that 3 week pulpal responses were slight to moderate and longer periods resulted in responses that were slight to none. We agree with Mjör and Swerdlow's recommendation that, in deep cavities, a liner should be used.

The bacteriological studies showed that the various amalgams had little to no inhibitory effect on the plaque samples or on the three most prominent human serotypes the metals are tightly incorporated into the amalgam and that they are unlikely to be released into the immediate environment of the amalgam. If the amalgams do not inhibit bacteria, they most likely would not be cytotoxic for tissue such as pulps and gingiva. Thus the lack of bacterial inhibition argues for the safety of these new copper amalgams in the oral tissues.

The minimal inhibitions that were noted among the various serotypes suggest that Dispersalloy ${ }^{\circledR}$ was the most active amalgam tested. This amalgam apparently released substances that slightly inhibit both broth and adherent growth of $S$. mutans in static systems. However, this small inhibition is not likely to be important in vivo as the inhibitors would quickly be diluted and removed by saliva.

\section{Acknowledgment}

The authors wish to thank Miss Kathleen R. Engelhard, and Messrs. John and James Baker and Thomas Ruprecht for their technical assistance.

\section{References}

American National Standards Committee MD156 for Dental Materials and Devices (1978) In Guide to Dental Materials and Devices, 8th edn. ADA. Recommended standard practices for biological and clinical evaluations. Chapter 16, 200-210.

Brännström, M. (1963) Reaction of the pulp to amalgam filling. Odontologisk Revy 14, 244-253.

Bratthall, D. (1972) Demonstration of Streptococcus mutans strains in some selected areas of the world. Odontologisk Revy 23, 401-410.

Cox, C. F., Heys, D. R. \& Heys, R. J. (1977) A gravity perfusion technique for lab animals. $L a b$ Animal July/August 6(4), 18-22.

Dixon, M. C. \& Rickert, U. G. (1933) Tissue tolerance to foreign materials. Journal of the American Dental Association 20, 1458-1472.

Effinger, V. A. (1954) Vergleichende histologische untersuchungen über die knochenmarksreaktion nach der implantation von cuprioydhaltigen zementen und vom kupferamalgam. Deutsche Zahnaerztliche Zeitschrift 9, 1289-1297. 
Espevik, S. (1977) In vitro corrosion of dental amalgams with different $\mathrm{Cu}$ contents. Scandinavian Journal of Dental Research 85, 631-636.

Granath, L. E. \& Hakansson-Holma, B. (1961) The occurrence of certain defects in copper amalgam restoration in the primary dentition. A comparison with silver amalgam restoration. Odontologisk Revy 12, 272-289.

Granath, L. E. \& Möller, B. (1971) Reaction of the human dental pulp to silver amalgam restoration. Effects of insertion of amalgam of high plasticity in shallow cavities. Acta Odontologica Scandinavica 29, 165-172.

Hill, T. J. \& Boester, K. W. (1934) Relative efficiency of germicidal cements. Journal of the American Dental Association 21, 1565-1571.

James, V. E. \& Schour, T. (1955) Early dentinal and pulpal changes following cavity preparation and filling materials in dogs. Journal of Oral Surgery $8,1305-1314$.

Langeland, K. (1963) Pulpal response to caries and operative procedures. Journal of the Dental Association of South Africa 18, 101-112.

Leirskar, J. (1974) On the mechanism of cytotoxicity of silver and copper amalgams in cell culture system. Scandinavian Journal of Dental Research 82, 74-81.

Loesche, W. J., Bradbury, D. R. \& Woolfolk, M. P. (1977) Reduction of dental decay in rampant caries individuals following short term kanamycin treatment. Journal of Dental Research 56, 254-265.

Loesche, W. J., Hockett, R. N. \& Syed, S. A. (1972) The predominant cultivable flora of tooth surface plaque removed from institutionalized subjects. Archives of Oral Biology 17, 1311-1325.

Manley, E. B. (1936) A preliminary investigation into the reaction of the pulp to various filling materials. Journal of the British Dental Association LX 7, 322-331, April.

Manley, E. B. (1942) Investigations into the early effects of various filling materials on the human pulp. Dental Record LXII 1, 1-16.

Manley, E. B. (1944) Pulp reaction to dental cements. Dental Record LXIV 4, 75-86.

Mathewson, R. J. (1970) Properties of copper and silver amalgams. Journal of Dentistry for Children Jan.-Feb. 38-44.

McCue, R. W., McDougal, F. G. \& Shay, D. E. (1951) The antibacterial properties of some dental restorative materials. Oral Surgery, Oral Medicine and Oral Pathology 4, 1180-1184.

Miller, W. D. (1890) Microorganisms of Human Mouth, pp. 238-242. Philadelphia: The S. S.
White Dental Manufacturing Company.

Mitchell, D. F. (1959) The irritation qualities of dental materials. Journal of the American Dental Association 5, 954-966.

Mjör, I. A., Eriksen, H. M., Haugen, E. \& Skogedal, O. (1977) Biologic assessment of coppercontaining amalgams. International Dental Journal 27(4), 333-340.

Mjör, I. A. \& Tronstad, L. (1972) Experimentally induced pulpitis, Oral Surgery, Oral Medicine and Oral Pathology 34 (1), 102-108.

Naegeli, S. (1893) Denkschriften der Schweiz, Naturforsh., Ges. 33:1. From Sheppard, M. S. (1935) The bactericidal action of pure metals and metal fillings. Dental Cosmos 77, 968-970.

Nygaard-Östby, B. (1955) Pulpareaksjoner ved fylinger av selvpolymeriserende plastmaterialer og amalgam. Odontologisk Tidskrift 63, 173-182.

Pickerill, H. P. (1909) The antiseptic value of fillings and dressings. British Dental Journal 30, 1185-1196.

Seelig, A. \& Lefkowitz, W. (1950) Pulp response to filling materials, New York State Dental Journal 16(10), 540-553.

Shay, D. E., Allen, T. J. \& Martz, R. F. (1956) The antibacterial effects of some dental restorative materials. Journal of Dental Research 35(1), 25-32.

Stanley, H. R., Swerdlow, H. \& Buonocore, M. G. (1967) Pulp reaction to anterior restorative materials. Journal of the American Dental Association 75, 132-141.

Staub, H. (1921) A contribution to the question of destructive action of metals on bacteria. Journal of the British Dental Association 42, 958-960.

Swerdlow, H. \& Stanley, H. R. (1962) Response human dental pulp to amalgam restoration ${ }^{5}$ Oral Surgery, Oral Medicine and Oral Pathology 15(4), 499-508.

Takahashi, K. (1975) A study of the cytotoxic action of gold-copper alloy by means of tissule culture. Journal of the Japanese Society for Dental Apparatus and Materials 16(35), 79-88.

Address:

Charles F. Cox

Laboratory of Oral Histology

5213 School of Dentistry

University of Michigan

Ann Arbor, Michigan 48109

USA 
This document is a scanned copy of a printed document. No warranty is given about the accuracy of the copy. Users should refer to the original published version of the material. 